\title{
Da janela do meu quarto: diálogos (im)prováveis
}

\section{Rafael de Almeida Tavares Borges}

\section{Resumo:}

A partir de uma análise do curta-metragem Da janela do meu quarto (2004), do cineasta e artista plástico Cao Guimarães, pretendemos refletir sobre a probabilidade de diálogos entre o domínio documental e a videoarte. Nesse contexto de pesquisa pretendemos considerar as influências dessas conversações, e suas implicações, para o que na contemporaneidade tendemos a nomear como documentário experimental.

\section{Palavras Chave:}

Cinema documentário, videoarte, documentário experimental.

\begin{abstract}
:
Analyzing the short movie Da janela do meu quarto (2004), by the filmmaker and plastic artist Cao Guimarães, we intend to study the dialogic probabilities between the documental environment and the video art. Regarding this research context we shall infer the implications and influences of such conversations to what we contemporarily tend to understand as experimental documentary.
\end{abstract}

\section{Keywords:}

Documentary cinema, video art, experimental documentary.

\section{A metáfora do lago}

Se considerarmos a realidade, híbrida e multifacetada, como a superfície de um lago, é possível que nos relacionemos com ele, ao menos, de três maneiras distintas: ou contempla-se a realidade do lago a partir de sua beira, do barranco; ou joga-se uma pedra em sua superfície para que a água reverbere e depois volte ao estado inicial; ou, ainda, é possível entrar efetivamente no lago, lançar seu corpo nele.

Essa é a maneira que, o cineasta e artista plástico mineiro, Cao Guimarães metaforiza as relações que ele mantém com a realidade para caracterizar seu trabalho. "Existe aí a possibilidade de um distanciamento, uma relação filtrada por um olhar distante, um olhar passante, algo que incide e elege, no momento mesmo do encontro entre a imagem que é dada e os olhos que a percebem" na instância apenas contemplativa daquele que observa o lago. Enquanto na posição daquele que lança a pedra, a intenção é de "desorganizar o aparentemente organizado. Essa pedra como um conceito, um dispositivo, uma proposição. Os trabalhos oriundos desse método são fundamentados no princípio de ação e reação". São obras que "jogam com a noção do esvaziamento da autoria ou, pelo menos, nutrem o desejo do compartilhamento desta". Já aquele que se joga corporalmente no lago "reflete um desejo de entrega e investigação, uma propensão ao embate, à mescla, a vivenciar um pouco mais de perto o que se esconde dentro do espelho" (1) (GUIMARÃES, 2007: 70-71).

Apesar de apontar essas três formas de lidar com a realidade, segundo ele, às vezes, quem domina é o acaso, esse acontecimento que surge sem um motivo aparente, no qual está plenamente implicada a idéia de caos. Da janela do meu quarto (2004 - 5') é prova disso. O curta-metragem, captado em um único rolo de Super-8, foi filmado da janela de um quarto de hotel quando Cao Guimarães já se preparava para 
ir embora de uma aula que havia dado em Belém do Pará.

\section{Poesia do real: o documentário em versos}

$\mathrm{O}$ acontecimento que mobilizou o olhar do artista naquele instante eram "dois corpos de criança" que "brigavam se amando e se amavam brigando" na areia molhada (2). Apesar de ter sido captado em filme Super-8, o material foi telecinado para vídeo e editado pelo próprio diretor em sua casa, tendo sido finalizado e exibido, sobretudo, em vídeo.

O que nos permitirá, no corpo desse trabalho, relacionar a obra Da janela do meu quarto à esfera do vídeo será, além desse fator da mudança de suporte para atender aos anseios do realizador, a premissa de uma imagem pensada pelo viés da mídia eletrônica, tanto pelo histórico das obras do realizador, quanto pela maneira que o artista constrói o objeto fílmico em si.

O documentário em questão, se nos é permitida algum tipo de categorização, é fortemente marcado pelo que Bill Nichols classificou como poético, em sua proposição dos modos do documentário, isto é, ele

[...] sacrifica as convenções da montagem em continuidade, e a idéia de localização muito específica no tempo e no espaço derivada dela, para explorar associações e padrões que envolvem ritmos temporais e justaposições espaciais. [...] Esse modo enfatiza mais o estado de ânimo, o tom e a o afeto do que as demonstrações de conhecimento ou ações persuasivas (NICHOLS, 2005: 138).

Segundo Nichols, documentários enquadrados nesse modo claramente mesclam elementos documentais e experimentais. E é justamente no encontro desses dois domínios que provavelmente encontramos "um locus por excelência da expansão e renovação das formas documentárias na contemporaneidade". Uma "vertente formativista, de vanguarda ou experimental, atenta às preocupações formais, estilísticas, expressivas, poéticas do documentário" (TEIXEIRA, 2007: 42) fazia frente ao viés realista hegemônico, desde o fim da década de 20.

Essa vertente que percebia na precariedade do dispositivo cinematográfico, e da perspectiva artificialis, um ponto de partida para a criação artística levou em conta as possibilidades instauradas por uma imagem-índice-documental que oferecia uma ordem de material riquíssimo à subjetividade dos realizadores em sua poiesis.

Isso porque colocava em primeiro plano o ato criativo, o ato produtivo das imagens em si motivadas pelo que pertence ao âmbito do subjetivo, do sensório, do imaginário, do emotivo. Desconsiderando, por essa perspectiva, a fabricação de imagens que se pautassem por um mero poder homologatório do real.

Nichols acrescenta que desde Dziga Vertov, são poucos os documentaristas que "adotam em seu trabalho assunção epistemológica básica de que a posição do ego em relação ao mediador do conhecimento - enquanto texto - são socialmente e formalmente construídos e devem se revelar como tal." Ou seja, o "processo de construção de significados se sobrepõe aos significados construídos (NICHOLS, 2005: 64).

Nesse sentido, o que temos é que, pela perspectiva de um documentário poético ou experimental, o realizador se nutre da experiência cinematográfica e dos recursos estilísticos provenientes desta como maneira de impregnar o seu objeto fílmico com um discurso declaradamente subjetivo, realidade improvável de se escapar, mesmo pelo viés realista ontológico, e induzir o espectador a uma leitura muito menos documentarizante - nos termos de Odin (2005) - como forma de alcançar informações acerca da 
realidade do mundo e das coisas, do que artística ou estética.

Dessa maneira, pode-se falar na presença de uma voz lírica nesse tipo de documentário, que não se preocupa em detalhar sua constituição, mas sim fazer asserções de uma forma marcadamente pessoal. Caso de Chuva (1929), de Joris Ivens, uma poesia em filme dedicada a revelar as relações do cineasta com as chuvas em Amsterdã, expondo seus sentimentos e impressões das coisas do mundo de maneira a nos remeter a uma percepção dilatada da temporalidade nas imagens. $O$ filme é utilizado como suporte capaz de compartilhar essas imagens-experiência que revelam uma imagem direta do tempo do acontecimento e nos permitem ver/sentir "um pouco de tempo em estado puro, mais que movimento" (DELEUZE, 1992: 78), nesse intento de relatar um dia, de chuva, na vida de uma grande cidade pela perspectiva de um olhar livre, nômade, que caminha pela cidade em todas as direções.

Foi no âmago da vanguarda que se formou a idéia de um ponto de vista ou voz diferente, que rejeitasse a subordinação da perspectiva à exibição de atrações ou à criação de mundos fictícios. [...] A maneira de o cineasta ver as coisas assumiu prioridade sobre a demonstração da habilidade da câmera de registrar fiel e precisamente tudo o que via NICHOLS, 2005: 124).

\section{Videoarte e documentário: diálogos}

De acordo com Arlindo Machado (2007), em As linhas de força do vídeo brasileiro, a irrupção do vídeo, em meados da década de 60, retoma esse espírito desconstrutivista das vanguardas do início do século e assume a imagem eletrônica como mídia privilegiada para a experimentação, pois, pela ontologia de sua natureza, ela é muito mais aberta e propícia às transformações e anamorfoses, se relacionada à imagem fotoquímica.

Não por acaso, a arte do vídeo, que se constitui tão logo os recursos técnicos se tornaram disponíveis, se definirá rapidamente como uma retórica da metamorfose: em vez da exploração da imagem consistente, estável e naturalista da figura clássica, ela se definirá resolutamente na direção da distorção, da desintegração das formas, da instabilidade dos enunciados e da abstração como recurso formal (MACHADO, 2007: 26).

Sem perder de vista o percurso que nos trouxe à imagem-vídeo, lembramos que segundo Bellour (1997) a imagem eletrônica pode se inclinar para, ao menos, dois caminhos: "pode ser posta a serviço da ilusão de realidade, como a maioria das imagens-filme." Pois apesar da diferente natureza de sua matéria, quando ela faz uso da analogia e da representação está muito próxima da imagem naturalista, apesar do caráter auto-referente do vídeo como suporte que garante uma espécie de realismo da materialidade. E, além disso, ela pode seguir pelo seu caráter onipotente de (de)composição, de tal maneira que "a ilusão da realidade se veja não mais apenas transgredida [...] como no cinema experimental, mas sobretudo relativizada, chamada a vacilar continuamente sobre si mesma" (BELLOUR, 1997: 177-178).

E é justamente nesta segunda instância que pontuamos Da janela do meu quarto. A obra se apresenta nesta fronteira cinema/vídeo, neste entre-imagens, que muito menos ficcionaliza uma realidade por um determinado ponto de vista, do que contempla a realidade de uma imagem indicial, pela qual, ao acaso, é atraído o olhar do artista. Ou seja, uma poética que relativiza a natureza do olhar. Machado acrescenta que

Em geral, as diversas gerações de videastas rejeitaram qualquer tipo de representação totalizadora, deixando patente nas obras as suas próprias dúvidas e a parcialidade de sua intervenção, ao mesmo tempo que se interrogavam sobre os limites de seu gesto enunciador e sobre a capacidade de conhecer realmente o outro. Com o vídeo, aquele que aponta suas câmeras para o outro não se 
encontra mais necessariamente numa posição privilegiada como produtor de sentidos, não está mais autorizado a dizer toda a verdade sobre o representado, nem está apto a dar uma coerência impossível a cultura enfocada. Os próprios realizadores não se encontram mais ausentes do 'texto' audiovisual, nem se escondem atrás das câmeras, de modo a sugerir uma pretensa neutralidade (MACHADO, 2007: 31).

Nesse contexto, a partir dessa posição de sujeito dos realizadores como produtores de discursos parciais, temos que as principais características da chamada videoarte serão: a mancha, como efeito pictórico; a lentidão/aceleração/repetição dos planos; a montagem interna ao quadro; o compartilhar da idéia de autoria com o espectador, que impulsiona ao surgimento de um novo leitor; a intermediaticidade; e a narratividade em um estado limite. Características essas que serão responsáveis por permitir um diálogo do documentário com a videoarte, o libertando de qualquer pretensão realista e permitindo que ele se assuma como poesia, como experimento.

O documentário experimental irá compartilhar do que, segundo Bellour, o cinema experimental e a videoarte buscavam escapar de todas as maneiras possíveis: "a onipotência da analogia fotográfica; o realismo da representação; o regime de crença da narrativa” (BELLOUR, 1997: 176). Será situado, então aí, nessa posição: em que emanações do real são matéria-prima para construções de novas realidades mediadas pelo olhar do sujeito; em que o realismo dá lugar ao formativismo e à poesia; e a narrativa segue em frágeis linhas à beira de um abismo.

\section{Da janela do meu quarto}

A partir de todo esse arcabouço teórico levantado, nos cabe aqui fazer uma breve análise de Da janela do meu quarto, levando em consideração seus materiais de composição, seus modos de composição, a narratividade documental (discutida a partir das funções ou modos de enquadramento da câmera) e, por fim, as modulações estilísticas - metodologia proposta por Elinaldo Teixeira em A propósito da análise de narrativas documentais - como forma de, em meio ao processo, reconhecer a proficuidade desse diálogo entre o documentário e a videoarte na obra.

O documentário conta com direção, fotografia e edição de Cao Guimarães e com trilha sonora do grupo O Grivo. Os cinco minutos do vídeo são compostos por apenas 12 planos agrupados em torno de uma única ação: a amorosa briga entre duas crianças, na areia, debaixo de chuva.

\section{Materiais de composição}

Os principais materiais de composição de que o diretor se utiliza para construir o objeto fílmico são basicamente: imagens/tomadas em primeira mão - realizadas para uso específico da obra, diferente de imagens de arquivo; a chuva - elemento suporte que envolve os personagens durante a ação e é sustentáculo para a temporalidade do filme; a areia - espaço onde se desenrola a ação dos personagens; a música - trilha incidental assinada pelo grupo $O$ Grivo, única fonte de sonoridade da narrativa, já que a mesma é destituída de voz off, depoimentos e entrevistas, e, também, de som direto; e os personagens reais/atores sociais - o casal de crianças.

Foram poucos os materiais de composição de que se valeu o documentarista, o que aponta para uma simplicidade da trama e para uma eleição bastante específica e direta dos objetos. O documentarista parece ter se apropriado, nesse sentido, de uma estética minimalista, que privilegia uma espécie de síntese artística marcada por uma seleção pontual de elementos essenciais para a narrativa, como forma de potencializar o efeito expressivo de cada um deles, em contraposição a uma tradição naturalista do documentário, por exemplo. A restrita quantidade de materiais de composição permitirá uma percepção 
expandida da relevância poética de cada material em si e também da maneira que eles se organizam, ao se relacionarem uns com os outros, durante a montagem.

\section{Modos de composição}

Os modos de composição, isto é, as formas que esses materiais se combinam por meio da montagem, para produzir sentido, são marcadas pela: colagem de materiais visuais e sonoros - foi sobreposta às imagens uma sonoridade, que se faz musical, ao utilizar ruídos que poderiam corresponder a reverberações do que as imagens indicam, como o próprio som da chuva; e dissociação entre o visual e o sonoro - apesar da utilização desse tipo de material sonoro que parece ter desembocado das tomadas, percebe-se uma intencionalidade na não sincronicidade desses materiais, o que sinaliza um caráter de fragmentação que enriquece ainda mais o trabalho de montagem.

É perceptível o uso de variações estruturais que dão a ver a alternância de sequiências previsíveis com improvisações inesperadas resultantes desse jogo que o artista mantém com o acaso - outra aproximação com uma estética minimalista. Podemos citar, ao menos, três exemplos: a) No quinto e sétimo planos, a possível previsibilidade das sequências entorno da brincadeira das crianças é rompida por uma variação sonora - a investida da criança menor (a menina), correndo em direção ao garoto, mais alto e esguio, movendo os braços em movimentos circulares de soco é intensificada pela trilha sonora, que tensiona aquele instante com o som das gotas de chuva aparentemente mais pesadas, como se a chuva estivesse passando por um momento de fúria, assim como a personagem; b) No nono plano vemos a garota no centro de um plano geral que dá a ver alguns galhos de uma árvore em sua porção superior. Ela está de joelhos e apoiada sobre suas mãos de perfil para a câmera, como que se recuperando para levantar. Diante disso, a outra criança, aparentemente mais velha, que está completamente de costas para a câmera apanha um galho fino da árvore e levemente bate no traseiro da outra por duas vezes. É o único instante em que a interação entre elas extrapola a utilização do próprio corpo, o que causa certa surpresa e parece remeter a uma fabulação acerca de um tipo de educação familiar, da qual elas provavelmente já foram vítimas; c) No décimo segundo plano, o último da obra, a câmera acompanha a menina que corre para cada vez mais longe da direita para esquerda do quadro, e o que aparentava ser apenas mais uma nova investida demonstra ser o fim da brincadeira, ao menos por ora. Isso porque a câmera fixa passa a revelar um plano cada vez mais geral que nos dá a ver que o garoto também está correndo, e à frente dela. E isso se mantém até que ambos saiam de quadro, se tornando cada vez mais distantes em relação à câmera/janela.

Além disso, essas imagens que possuem como marca de origem o hibridismo, perceptível pela dupla camada de referencialidade a que se submeteram - os pixels do vídeo sobrepostos aos característicos grãos do Super-8, são embutidas de uma vagarosidade propositiva que nos despertam para uma delicada plasticidade do real. E quando, aqui, nos referimos a realismo, não o consideramos como uma adequação análogo-mimética entre signo e referente, mas, sim, por um viés deleuziano, à percepção da duração vivida.

Esse efeito de lentidão, pensada segundo o diretor já durante a captação das imagens e manipulado durante a montagem, aos poucos dá-nos a sensação de estar em contato direto com o tempo, um tempo do acaso, apreendido em blocos e em distintas camadas. Um tempo que é deslocado, suspenso, de uma possível linha cronológica, que não é o presente e tampouco o passado ou o futuro. É o tempo do acontecimento, dessa imagem que não o representa, mas o é.

De um a outro, dos materiais aos modos de composição, da eleição ao arranjo desses materiais, podemos inflexionar para uma compreensão a respeito da mudança do plano de imanência em um plano de organização/composição (DELEUZE \& GUATTARI, 1992). Considerando o caos como o aparecer e o desaparecer simultâneo de singularidades (multiplicidades), os planos de imanência poderiam ser 
percebidos como a maneira para se conduzir o pensamento nesse mundo de variabilidades. De maneira metafórica, poderíamos considerar esse plano como uma rede (teia), a qual poderia ser levada a vibrar, ou não, de acordo com a singularidade que a tocasse. E a organização dessas variabilidades, que sensibilizaram o plano de imanência, o apontaria rumo a um plano de composição.

Em nossa análise, o acontecimento - esse virtual sempre incorporado no estado das coisas, porém que não se esgota nele, habitante de um tempo morto em que nada se passa (DELEUZE, 1992) - que tensiona a rede do artista, e o permite traçar um plano sobre o caos, é do campo do trivial, do comum, do ordinário: duas crianças que brincam de brigar embaixo de chuva. E é, em especial, a maneira que o documentarista organiza esses materiais (plano de composição) por intermédio de seu olhar, da escolha do plano à montagem, que nos garante sensações por meio de figuras estéticas que transbordam a realidade com poesia, e que ao invés de nos dar a ver um mero retrato do acontecimento, nos joga em uma realidade artística multiplicadora do caos. Realidade essa que suspensa de um espaço bem demarcado, de uma temporalidade cronológica e circunscrita por uma lógica indiciária da imagem é capaz de suscitar o aparecimento de outras imagens: vindas do pensamento, de lembranças, da memória.

\section{Narratividade documental}

Em relação à narratividade, o documentário é realizado todo com câmera na mão, mas apesar disso a câmera apresenta pouca movimentação, com suaves e longos planos-sequências. Em sua maior parte os planos são fixos, ou o mais próximo possível disso, e munidos de um ar propositadamente contemplativo - características essas que, mais uma vez, nos permitem aproximá-lo de uma estética minimalista.

O posicionamento da câmera vai de encontro ao que o título do filme anuncia, de um sujeito da câmera que está na janela de seu quarto, a observar o que se passa do outro lado: aquele encontro-embate coreográfico entre os corpos daquelas crianças, até que uma delas sai correndo, fugindo. Nesse sentido, conseguimos, em um primeiro instante, levar em consideração o anúncio, Da janela do meu quarto, e reconhecer esse enunciador que vê o que se passa através de uma câmera subjetiva direta do personagem/sujeito-da-câmera (indicador de um modelo narrativo direto-indireto (3)). No entanto, com o passar do tempo, as tomadas parecem ser possuídas por um princípio de incerteza, onde já não é mais possível discernir as imagens como sendo a visão de uma câmera, ou de um personagem; como objetivas, ou subjetivas e o caos se (re)apropria, das imagens e, dessa experiência do espectador, o sensibiliza a assumir um novo papel nesse jogo instaurado por essa frágil realidade: que ele também apenas se coloque na janela, e contemple. Para Pasolini esta indiscernibilidade, que caracteriza uma subjetiva indireta livre, é "a marca por excelência de um cinema de poesia, doravante liberto da vontade de contar histórias, lançando-as e truncando-as em pseudonarrativas mas, sobretudo, empenhado na criação de 'verdadeiras páginas líricas"” (TEIXEIRA, 2000: 85).

\section{Modulações estilísticas}

Diante do ponto de vista estilístico, que nos abre para uma reflexão mais generalizante dentro da teoria documental, poderíamos dizer que percebemos no filme uma forte exploração da indeterminação da tomada e uma neutralização do olhar, traços característicos da primeira vaga do cinema direto. No entanto, não é o que ocorre em Da janela do meu quarto. $\mathrm{O}$ realizador não estava na janela à espreita de uma imagem-intensa (4). É tudo muito menos uma busca por uma estética do observacional, do que fruto do acaso e da sensibilidade do documentarista em captar uma das esferas dessas realidades múltiplas que nos cercam a todo o tempo, variabilidades pulsantes constantemente se movimentando entre o mostrar e o se esconder em um mundo de variação universal.

O cinema direto norte-americano, reconhecido como o primeiro momento do cinema direto, irá 
reivindicar para si uma estética da "mosca na parede", isto é, será pautado pela observação e não intervenção do cineasta diante do que se passava diante da câmera. Baseado por um princípio ético do recuo, ele "não questiona o saber em si [...], mas aponta para a necessidade de esse saber ser constituído pelo próprio sujeito no exercício de sua liberdade" e para que isso seja possível "defende a necessidade de a representação ser ambígua" (RAMOS, 2005: 177), diferentemente do que é visto no documentário clássico, característico por sua voz do saber atuante em termos morais e ideológicos.

Esse recuo do sujeito que enuncia visa o realce desse "paralelepípedo do real" que garante a liberdade do espectador. Nesse sentido ficamos impossibilitados de falar sobre traços estilísticos do "modo observacional" em Da janela do meu quarto, a não ser que o percebamos deslocados de sua intenção original. Aqui o plano-sequência, e sua prerrogativa de um alcance direto à realidade no cinema direto, ganha uma dimensão completamente subjetiva com a montagem, pela qual temos a impressão de as imagens captadas terem se organizado por uma espécie de ressonância mútua, e a manipulação das imagens. A não intervenção do cineasta não aparenta ter a intenção de garantir uma imparcialidade ou de se pautar por uma estilística do recuo, assemelha muito mais ser fruto de um olhar do acaso que se vê atraído por um acontecimento inesperado, por uma virtualidade que se tornou atual/visível. As vozes dialógicas, características do cinema direto, não existem em Da janela do meu quarto, que como vimos é destituído inclusive de som direto. A busca da anulação da voz do documentarista, em prol de uma liberdade do espectador, também não é plenamente reconhecível em nosso objeto - de fato, não encontramos uma voz verbal; no entanto, o documentarista assere a todo o tempo, de uma maneira pessoal, imprimindo uma voz poética e lírica por intermédio do tratamento das imagens e sons.

\section{Considerações finais}

A nossa intenção aqui é de relativizar as aproximações da obra em análise com esse modo de observação do documentário, que parecem tão latentes na superficialidade. E, dessa maneira, apontar para o uso desses recursos de estilo, potencializados pelas estéticas videográficas, que foram capazes de metamorfosear o documentário moderno em pós-moderno, com um "estilo de forte presença poética, no qual os enunciados sobre o mundo são marcados por uma sensibilidade esteticista que se afirma e se estampa como estilo", e com pretensões que estão distantes da objetividade do saber "esse enunciado turvado/poético volta-se para a fala em ritmo e o discurso da poesia, valorizando formas imagéticas que distorçam a forma perspectiva da imagem-câmera" (RAMOS, 2005: 183).

O acaso, esse outro fator marcante das vanguardas históricas, retomado pela videoarte, e sempre presente no documentário, é o grande fator confluente para a garantia de tamanha beleza e expressividade em uma obra que ao mesmo tempo documenta e poetiza o real, que experimenta habitar uma fronteira, depois de já ter nascido de uma.

O acaso não diz respeito aqui apenas ao desvio de um projeto inicial, mas a todo espaço que naturalmente surge para interferências alheias aos objetivos do artista. Movimentos caóticos, atitudes gratuitas, acidentes de toda espécie ganham eficiência na medida em que o processo permite reversibilidade. Isto é, tem-se no acaso um instrumento que oferece um número inesgotável de possibilidades que podem ser corrigidas caso não correspondam às necessidades do artista (ENTLER, 2005: 277).

E apostando nessa reversibilidade, Cao Guimarães investe em um caráter inventivo do documentário que lhe garante uma inflexão predominantemente ensaística, característica recorrente em suas obras. Isto é, o autor se assume, deixando marcas e manchas enquanto escreve seu discurso com sua câmera-caneta, e se compromete concomitantemente com a sua subjetividade e a realidade, se é que já houve como se fugir disso, expressando seus pensamentos por mais abstratos que eles sejam. Por essa veia experimental, o 
documentarista realiza

[...] um trabalho de pensamento que se debruça sobre suas matérias para moldá-las e manipulá-las conforme propósitos que não estão dados nelas, que não são evidentes e que bastaria sua exposição, mas segundo aqueles que nascem da relação mesma do documentarista com os entornos que sua vista ou imaginação alcançam, com seus objetos, agentes ou personagens implicados, suas derivas, oscilações, dúvidas em relação ao processo de criação que raramente se esgota num resultado pronto e acabado (TEIXEIRA, 2007: 43).

Nesse sentido, o que se percebe na contemporaneidade é esse diálogo produtivo entre o documental e a videoarte, pois como bem lembra Arlindo Machado, por suas "próprias características, os meios eletrônicos se prestam muito pouco a uma utilização naturalista, a uma utilização meramente homologatória do 'real'." E reitera, "pelo contrário, se a 'realidade' comparece em alguma instância nessas atividades, ela se dá como decorrência de um trabalho de escritura" (MACHADO, 2007: 30).

Da janela do meu quarto nos convida a compartilhar dessa escritura, a preencher essas lacunas que vão sendo deixadas e a partilhar da construção desses significados. Convida-nos também, como indivíduos sociais que somos, a manter uma nova relação com as instâncias do real que nos cercam. Impulsiona-nos a traçar planos de imanência sobre a superfície desse lago que é a realidade, lançando redes no lago que filtrem as singularidades que serão privilegiadas por nós. E em meio a esse fluxo perceber que posição somos levados a assumir diante do lago/realidade a cada instante: se à beira, lançando objetos, ou dentro dele. Ou, ainda, por acaso, em uma janela.

\section{Bibliografia:}

BELLOUR, Raymond. Entre-imagens - Foto, cinema, vídeo. Campinas: Papirus, 1997.

DELEUZE, Gilles. Conversações, 1972-1990. Campinas: 34, 1992.

DELEUZE, Gilles \& GUATTARI, Félix. O que é a filosofia?. Campinas: 34, 1992.

ENTLER, Ronaldo. "Fotografia e acaso: a expressão pelos encontros e acidentes". In: SAMAIN, Etienne (org.). O fotográfico. São Paulo: Hucitec/Editora Senac, 2005.

GUIMARÃES, Cao. "Documentário e subjetividade - Uma rua de mão dupla". In: Equipe Itaú Cultural (org.). Sobre fazer documentários. São Paulo: Itaú Cultural, 2007.

MACHADO, Arlindo. “As linhas de força do vídeo brasileiro”. In: MACHADO, Arlindo (org.). Made in Brasil. São Paulo: Iluminuras, 2007.

NICHOLS, Bill. “A voz do documentário”. In: RAMOS, Fernão Pessoa (org.). Teoria Contemporânea do Cinema. Volume 2. São Paulo: Editora Senac, 2005.

. Introdução ao documentário. São Paulo: Papirus, 2005.

ODIN, Roger. "A questão do público: uma abordagem semiopragmática”. In: RAMOS, Fernão Pessoa (org.). Teoria Contemporânea do Cinema. Volume 2. São Paulo: Editora Senac, 2005.

RAMOS, Fernão Pessoa. "A cicatriz da tomada: documentário, ética e imagem-intensa”. In: RAMOS, 
Fernão Pessoa (org.). Teoria Contemporânea do Cinema. Volume 2. São Paulo: Editora Senac, 2005.

TEIXEIRA, Francisco Elinaldo. "A propósito da análise de narrativas documentais". In: CATANI, Afrânio Mendes; GARCIA, Wilton; FABRIS, Mariarosaria (orgs.). Estudos Socine de cinema. ano VI. São Paulo: Nojosa, 2005.

. “Cinema e poéticas de subjetivação". In: BARTUCCI, Giovanna (org.). Psicanálise, cinema e estéticas de subjetivação. Rio de Janeiro: Imago, 2000.

. "Documentário expandido: reinvenções do documentário da contemporaneidade". In: Equipe Itaú Cultural (org.). Sobre fazer documentários. São Paulo: Itaú Cultural, 2007.

\section{Notas:}

Trabalho apresentado no NP Audiovisual do IX Encontro dos Grupos/Núcleos de Pesquisa em Comunicação do XXXII Congresso Brasileiro de Ciências da Comunicação (Intercom).

(1) "Sopro", "Hypnosis", "Word/World" e "Nanofania" são exemplos de obras do diretor que correspondem à primeira posição. "Rua de mão dupla", à segunda. E "A alma do osso" e "Andarilho", à terceira e última.

(2) Cao Guimarães, na sinopse da obra.

(3) Consideramos aqui dois modelos de narratividade: a) direto-indireto: aquele através do qual é possível perceber os pontos de vista da câmera (objetiva indireta) e dos personagens (subjetiva direta); b) indireto livre: aquele em que existe uma indiscernibilidade entre o que câmera e personagens vêem.

(4) "A imagem-intensa é uma imagem-qualquer que, na sucessão das infinitas constelações espaciais de ação/reação dos agentes, recebe a carga do extraordinário transformando-se em 'única" (RAMOS, 2004).

\section{Mini Currículo :}

Mestrando do Programa de Pós-Graduação em Multimeios da Universidade Estadual de Campinas (Unicamp). 